Original Article

\title{
A PROSPECTIVE OBSERVATIONAL STUDY ON PREVALENCE OF HYPOTHYROIDISM IN A TERTIARY CARE TEACHING HOSPITAL
}

\author{
N. SWATHI ${ }^{*}$, VOLETI. VIJAYA KUMAR ${ }^{1}$, M. FARJANA ${ }^{1}{ }^{*}$, M. VISHNU VARDHAN ${ }^{1}$, M. MUNENDRA ${ }^{1}$, G. VIJAY KUMAR ${ }^{2}$
}

${ }^{1}$ Department of Pharmacy Practice, Santhiram College of Pharmacy, Nandyal, Kurnool (Dist), ${ }^{2}$ Department of General Medicine, Santhiram Medical College and General Hospital, Nandyal, Kurnool (Dist)

Email: nomulanani4798@gmail.com

Received: 25 Jan 2018 Revised and Accepted: 20 Apr 2018

ABSTRACT

Objective: To determine the prevalence of hypothyroidism in a rural population of Nandyal.

Methods: A prospective study was conducted in Santhiram medical college and general hospital, Nandyal from July 2017 to December 2017 , to study the prevalence of hypothyroidism among the population.

Results: In this study, 1000 patients were evaluated for the thyroid functioning, among them $\mathrm{n}=104(10.4 \%)$ showing positive results in hypothyroidism. The positive 104 patients showed that $n=63(60.57 \%)$ of the population are in the age limit of 21-40. Out of the same population are $\mathrm{n}=11(10.6 \%)$ are male and female are $\mathrm{n}=93(89.43 \%)$. In age group distribution more prevalence was observed in 21-30 y of age group $\mathrm{n}=36$ (34.61\%). In this study, sub-clinical hypothyroidism was prevalent in females $\mathrm{n}=80(76.92 \%)$ than males $\mathrm{n}=10(9.61 \%)$.

Conclusion: Our study demonstrates that hypothyroidism was higher in a female with age group as 21-40 y and there is a significant prevalence of hypothyroidism in the study population.

Keywords: Hypothyroidism, Prevalence study, Chi-square test

(C) 2018 The Authors. Published by Innovare Academic Sciences Pvt Ltd. This is an open access article under the CC BY license (http://creativecommons.org/licenses/by/4.0/] DOI: http://dx.doi.org/10.22159/ijpps.2018v10i6.24958

\section{INTRODUCTION}

Worldwide about 1 billion people are estimated to be iodine deficient however, it is unknown how often this results in hypothyroidism [1].

The Prevalence of hypothyroidism in the world is about 4-8\% [1].

Thyroid diseases are the commonest endocrine disorders worldwide, India too is no exception. It has been estimated that about 42 million people in India suffer from thyroid disease. Hypothyroidism is characterized by an overt state of myxedema, multisystem failure to an asymptomatic or sub-clinical condition with normal levels of thyroxine (T4) and triiodothyronine (T3) and mildly elevated levels of serum thyrotropin [2-4].

Serum TSH measurement is the most convenient and sensitive method for screening of hypothyroidism because there is a linear relationship with serum TSH and circulating thyroid hormone level. Hypothyroidism can occur if the thyroid gland fails to work properly or if the thyroid gland is not stimulated properly by the hypothalamus or pituitary gland [5-8].

The risk of hypothyroidism is higher in people with a family history of thyroid disease and those aged over $60 \mathrm{y}$. Hypothyroidism is most commonly affects women, from middle age onwards, but it can occur at any age $[9,10]$. There are no national wide studies on the prevalence of hypothyroidism from India either in the pre or post iodization periods. Hence a large cross-sectional, comprehensive and prospective study was required to provide a clear picture of the evolving profile of thyroid disorders across the whole country, especially as the country is in the post iodization era [11]. The main aim of this study was to find out the prevalence of thyroid disorder among the population of Nandyal and to create awareness among the population about the disorder so that adequate management is possible which will prevent developing of further systemic complications related to abnormal thyroid status [12].

\section{MATERIALS AND METHODS}

\section{Study design}

This was prospective, an epidemiological study conducted in Santhiram medical college and general hospital, this study was carried out from July 2017 to December 2017.
The study was reviewed and approved by Institutional Ethical committee (Registration No: IECR/05/SRMCGH/AP/2017. A total of 104 cases of thyroid abnormality were found during this study period. The data was collected from the patients that referred to a central laboratory, of our hospital for thyroid function test, which includes T3, T4 and TSH.

\section{Enrollment criteria}

All male or female subjects referred to a central lab for the thyroid function test were included. Participants were excluded if they were thyroid ablation persons and the subjects having the chronic systemic illness or if they were receiving drugs that could interfere with thyroid function test [13].

\section{Study procedure}

All the subjects underwent medical history assessment, general clinical examination, before enrollment including examination of thyroid glands. Evaluation of thyroid profile was done in the central clinical laboratory of our hospital.

Assess for thyroid hormone T3, T4, and TSH was performed by ECL technology. Based on previous thyroid history and current thyroid function test results participants were classified using following definitions like Sub-clinical hypothyroidism and overt hypothyroidism. The Prevalence of different thyroid function disorders was summarized as count and percentage. A chi-square test was used to determine the trends in the Prevalence of the disorder among different age group and genders.

\section{RESULTS}

Hypothyroidism is a lifelong chronic condition particularly prevalent in women and the elders. The present study was initiated from July 2017 to December 2017; in this study, we assessed the prevalence of hypothyroidism in all age group of patients in Santhiram general hospital. There are several important findings from this prospective analysis of 1000 , subjects who underwent screening for abnormal thyroid function. Based on T3 (80-220ng/dl), T4 (4.5-11.5 $\mu \mathrm{g} / \mathrm{dl})$ and TSH (0.5-5mIU/l) observational levels, subjects with abnormal 
T3, T4 and TSH levels were categorized into hypothyroidism patients. Hypothyroidism was found to be a common form of thyroid dysfunction affecting 104 subjects (10.4\%) of the study population.
Among the 104 hypothyroidism patients the prevalence of female patients $n=93(89.42 \%)$, were more when compared with male patients $n=11(10.6 \%)$, this data was tabulated in table 1 .

Table 1: Gender wise distribution of hypothyroidism patients

\begin{tabular}{lll}
\hline Gender & Total No. of patients(n=104) & Percentage \\
\hline Male & 11 & $10.6 \%$ \\
Female & 93 & $89.42 \%$ \\
\hline
\end{tabular}

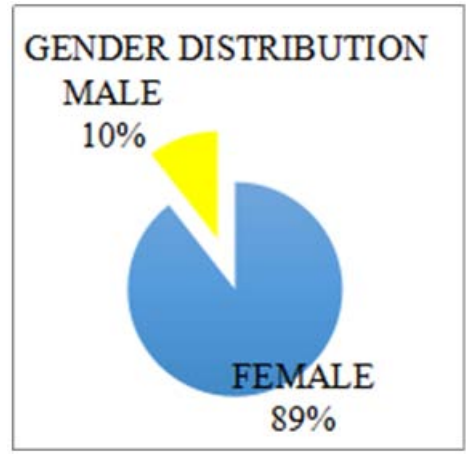

Fig. 1: Gender wise distribution of hypothyroidism patients

Chi-square test demonstrated a statically significant $(p<0.05)$ interaction of subjects, gender with the prevalence of hypothyroidism. In age group distribution more prevalence was observed in 21-30 y of age group $n=36$ (34.61\%), followed by 31-40 $y$ of age group $n=27(26 \%)$, less than or equal to $20 \mathrm{y}$ of age group $\mathrm{n}=15(14.42 \%), 41-50$ y of age group $\mathrm{n}=11(10.57 \%), 51-60$ y of age group $n=9(8.7 \%),>61$ y of age group $n=6(5.7 \%)$, this data was tabulated in table 2 .

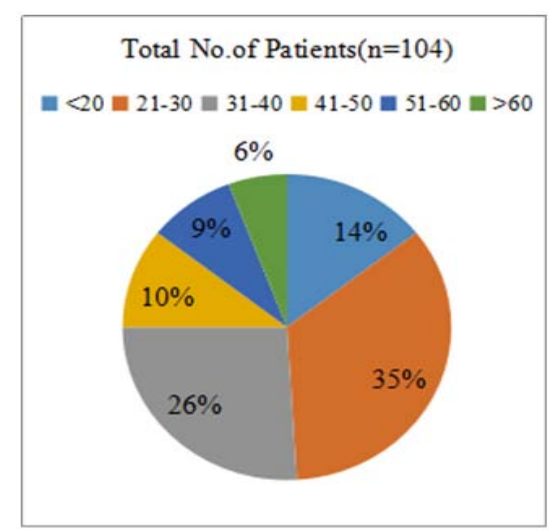

Fig. 2: Age wise distribution of patients

Table 2: Age wise distribution of patients

\begin{tabular}{llll}
\hline S. No. & Age group in years & Total No. of patients $(\mathbf{n = 3 0 0 )}$ & Total \% of the distribution \\
\hline 1. & $<20$ & 15 & 14.42 \\
2. & $21-30$ & 36 & 34.61 \\
3. & $31-40$ & 27 & 25.96 \\
4. & $41-50$ & 11 & 10.57 \\
5. & $51-60$ & 9 & 8.7 \\
6. & $>60$ & 6 & 5.76 \\
\hline
\end{tabular}

In the current study, we assessed the Prevalence of thyroid disorders particularly hypothyroidism in population residing in Nandyal. Hypothyroidism was found to be a common cause of thyroid dysfunction affecting $9.76 \%$ of the population, the similarity with a study conducted in other parts of India suggesting the nationwide higher Prevalence of hypothyroidism in India. Hence it requires the regular monitoring of thyroid status, of the population who are at greater risk of developing hypothyroidism particularly in the adult group $[13,14]$. There was a predominance of hypothyroidism in women in our study and is consistent with worldwide report especially those in midlife. The Prevalence fig: 2. noted for women in the study to draw an attention for the growing health needs of this important segment [15]. The Prevalence of sub-clinical hypothyroidism was also high in the study. In this study, sub-clinical hypothyroidism was present in female $76.92 \%(\mathrm{n}=80)$ and males $9.61 \%(\mathrm{n}=10)$, this data was tabulated in table 3 .

Limitation of the current study was that it was an observational study. Therefore a controlled study would be more appropriate to confirm the association of Hypothyroidism and its complications. Moreover, the screening tests for complications of hypothyroidism were done only once. To get accuracy, this should have to be performed repeatedly for their confirmation.

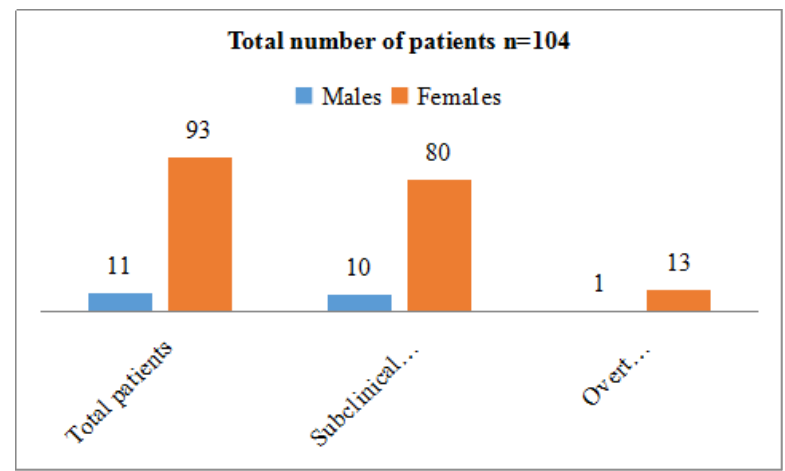

Fig. 3: Classification of patients based on thyroid profile

Table 3: Classification of patients based on thyroid profile

\begin{tabular}{lllll}
\hline S. No. & Particulars & Males & Females & Total percentage of distribution \\
\hline 1. & No of patients with Overt Hypothyroidism $(\mathrm{n}=14)$ & 1 & 13 & 13.46 \\
2. & No of patients with Subclinical Hypothyroidism $(\mathrm{n}=90)$ & 10 & 80 & 86.53 \\
\hline
\end{tabular}




\section{CONCLUSION}

Our study suggests that Hypothyroidism is the most prevalent disease in the rural population of Nandyal in both males and females. It was proved that hypothyroidism was higher in a female with age group as 21-40 y. The severity of hypothyroidism was increased with age group. Prevalence of overt hypothyroidism is around $12.46 \%$ and subclinical hypothyroidism is around $76.92 \%$ in females. Hence, Prompt detection and corrective treatment with thyroxine can prevent many complications. Therefore, routine testing with serum TSH is a sufficient and cost-effective screening tool.

\section{ACKNOWLEDGEMENT}

The authors wish to thank Dr. M. Santhiramudu Chairman of Santhiram College of pharmacy and Dr. C. Madhusudhana Chetty, Principal of Santhiram College of Pharmacy for providing the facilities to complete this research work.

\section{ABBREVIATION}

ECL-electro-chemiluminescence

T4-thyroxin

T3-triiodothyronine

TSH-thyroid stimulating hormone

IEC-institutional Ethical Committee

\section{AUTHORS CONTRIBUTIONS}

All the author have contributed equally

\section{CONFLICT OF INTEREST}

The authors have no conflict of interest

\section{REFERENCES}

1. Renuka P, Akila S, Ebenezer W. Prevalence of metabolic syndrome and its components in women with subclinical hypothyroidism. Asian J Pharm Clin Res 2013;6:82-4.

2. National Guidelines for Screening of Hypothyroidism during Pregnancy, Ministry of Health and Family Welfare, Government of India; 2014.
3. Negro R, Stagnaro Green A. Diagnosis and management of subclinical hypothyroidism in pregnancy. $\mathrm{Br}$ Med J 2014;349-429. https://doi.org/10.1136/bmj.g4929

4. Ambika Gopalakrishnan Unnikrishnan, Sanjay Kalra, Rakesh Kumar Sahay, Ganapathi bantwal Mathew john, Neeraj Tewari Prevalence of hypothyroidism in adults: an epidemiological study in eight cities of India. Indian J Endocrinol Metab 2013:17:647-52.

5. Saraladevi R, Nirmala Kumari T, Shreen B, Usha Rani V. Prevalence of thyroid disorder in pregnancy and pregnancy outcome. Int Arch Integrated Med 2016;3:1-11.

6. Rajalakshmi MS, Singh AK, Sujit D, Samchetsabam RD. The fetomaternal outcome in maternal hypothyroidism complicating pregnancies at RIMS: a prospective study. Eur J Pharm Med Res 2016;3:452-9.

7. Ali J Chakra. Primary hypothyroidism current approaches and future possibilities. Drug Des Devel Ther 2012;6:1-11.

8. Mark PJ Vanderpump, W Michael G, Tunbrige. Epidemiology and prevention of clinical and subclinical hypothyroidism. Thyroid 2004;12:839-47.

9. Gupta G, Sharma P, Kumar P, Sharma R. Scope of inflammatory markers in subclinical hypothyroidism. Asian J Pharm Clin Res 2015;8:24-7.

10. David J Stitt, MB MD. Thyroid hormone therapy for older adults with subclinical hypothyroidism. N Engl J Med 2017;376;2534-44

11. Yussuf AY, Bhogireddy N, Vulli V, Verma A, Bhaskaran AA. Thyroid stimulating hormones and free thyroxine as an indication of thyroid dysfunction at pathology laboratory of Mnazi Mmoja Hospital, Zanzibar. Asian J Pharm Clin Res 2014;7:67-71.

12. Canaris GJ, Manowitz NR, Mayer G, Ridgway EC. The colorado thyroid disease prevalence study. Arch Intern Med 2000;160:526-34.

13. RZ Klein. Prevalence of thyroid deficiency in pregnant women Clin Endocrinol 2015:35:41-6.

14. Srinivas Rao, Anitha Patibandla. A study to find out the prevalence of hypothyroidism among pregnant women visting ESI hospital sanathnagar Hyderabad, OB/Gyn; 2016. p. 6.

15. Mannisto T, Vaarasmaki M, Hartikainen AL. Perinatal outcome of children born to mothers with thyroid dysfunction or antibodies: a prospective population-based cohort study. J Clin Endocrinol Metab 2009;94:772-9. 